\title{
"Words Speak Louder than Actions": The Connection between Gendered Language and Bullying Behavior
}

\author{
Nicole L. Rosen ${ }^{1}$, Nicole A. Shoenberger ${ }^{2}$ \\ ${ }^{1}$ The Ingenuity Project, Baltimore Polytechnic Institute, Baltimore, USA \\ ${ }^{2}$ Loyola University Maryland, Baltimore, USA \\ Email: rosen@ingenuityproject.org,nshoenberger@loyola.edu
}

How to cite this paper: Rosen, N. L., \& Shoenberger, N. A. (2021). "Words Speak Louder than Actions": The Connection between Gendered Language and Bullying Behavior. Open Journal of Social Sciences, 9, 197-214.

https://doi.org/10.4236/iss.2021.98014

Received: July 22, 2021

Accepted: August 8, 2021

Published: August 11, 2021

Copyright $\odot 2021$ by author(s) and Scientific Research Publishing Inc. This work is licensed under the Creative Commons Attribution International License (CC BY 4.0).

http://creativecommons.org/licenses/by/4.0/

\begin{abstract}
Gender inequalities have been examined at individual and institutional levels. One key way that gender differences are reinforced is through language. To examine gendered language differences, this study goes beyond what girls and boys say to examine how they describe their experiences, pertaining specifically to bullying. The central research question of this study is, "How do girls and boys interpret and explain their experiences of being bullied?" Using open-ended questions from a national survey, this study applies a qualitative content analysis and OSL regression analysis to determine how gender socialization has influenced how girls and boys communicate their experiences. Findings include girls' tendency to offer in-depth responses, which reflect storytelling, while boys minimized their victimization by giving off a tough front. This study suggests that gendered patterns of language serve to reinforce gender differences in how girls and boys reflect on their experiences with bullying.
\end{abstract}

\section{Keywords}

Gender, Language, Bullying, Sociolinguistics, Socialization

\section{Introduction}

Gender differences are taught, internalized, and carried out at various levels of interaction. Children learn early on what gender roles they are expected to fulfill and receive various sanctions, should they break away from "appropriate" gender behavior. For instance, boys who display feminine characteristics are often called "sissy," whereas girls who take on masculine traits are considered 
"bossy" or "bitchy" (Johnson, 2005). Agents of socialization reinforce the gender binary, which views masculinity and femininity as two distinct and exclusive genders (Bem, 1993; Lorber, 1994). Obvious ways that the gender binary is reinforced is through clothing, toys, and playgroups. Less obvious, however, is how girls and boys are taught to use language. Not only do children learn appropriate gender roles of "doing" femininity or masculinity, there is also gender-appropriate linguistic behavior (Coates, 2004; West \& Zimmerman, 1987). As a result, patterns of communication reflect the expected behaviors associated with one's sex. There are many situations in which children interact that may demonstrate these differences in communication patterns. One way to investigate gendered communication is to examine specific types of situations that are shared by many children, such as bullying.

\section{Background}

Much literature on bullying focuses on who commits the act, as well as the type, causes, and effects of bullying. Concentration has also focused on what schools, parents, and communities do to reduce and respond to bullying. Lacking from previous studies are written descriptions and explanations from children themselves. Allowing victims to write about their experiences offers youth a level of anonymity, which is not possible when using other qualitative methods (i.e. focus groups, interviews, or participant observation). The purpose of this article is to expand on previous understandings of gendered bullying behavior (direct or indirect) (Olweus, 1993) to examine how gendered bullying is also reflected in written language. This study examines what the victims write, how much the victims write (quantity), as well as gendered language patterns they provide in their accounts. By using written accounts, we may understand how gender influences how girls and boys make sense of their experiences of being bullied. Qualitative data are further supported by statistical analyses to determine any significance in the frequency of words used and the length of responses. Children learn "through the use of language" and are "socialized to use language" (Schieffelin \& Ochs, 1986: p. 163 emphasis added). Language, thereby, serves as a means for children to gain a sense of their social order, which includes appropriate gender roles (Schieffelin \& Ochs, 1986). Understanding the connection between language and gender amongst youth, may be best understood by focusing on a common lived experience for many school-aged children: bullying. Children may (unknowingly) reinforce or challenge gender inequalities by how they use language when engaging in and making sense of bullying behavior. The following is a discussion on understanding language socialization as it pertains to gender.

\subsection{Learning Gender through Language}

Linguistics is the scientific study of language, which seeks to understand the "nature and workings of language" (Cameron, 1992: p. 18). Often, one's gram- 
mar, phonology (sounds in language), lexicon (vocabulary or wordbook), and syntax (order of words) are the primary focus when interpreting language (for examples see Coates, 2004; Weatherall, 2002). Sociolinguistics, on the other hand, is a subcategory of linguistics and focuses on language and social interaction (Cameron, 1992). Sociolinguistics examine how social interaction influences language and how language is shaped by society.

Theoretically, sociolinguistics is influenced by sociology and feminism (Cameron, 1992) and contends that gender inequalities are reflected in language (Trudgill, 1995). Sociolinguistic Deborah Tannen (1990) takes a cross-cultural approach to gender and language and asserts that women and men speak different dialects, or "genderlects," but neither style is superior to the other. Linguistic lessons learned in childhood and adolescence shape these different linguistic patterns as adults, which may reinforce gender differences. For instance, girls are encouraged to be more talkative than boys and routinely outscore boys in verbal competence, from infancy to early adolescence (Coates, 2004). Girls learn language faster than boys and some studies suggest that girls “... are superior in terms of comprehension, size of vocabulary, reading ability, handling of complex expression such as the modals, etc." (Coates, 2004: pp. 149-150; Weatherall, 2002). Also, girls are socialized through language to be verbally expressive and polite (Lakoff, 1975; Speer, 2005).

For example, patterns of women's language include the use of tag questions, rising intonations, and use of "hedges" which includes words such as "well" and "kinda" (Lakoff, 1975; Speer, 2005). The result of these patterns reinforces the notion that women's speech is not taken seriously. Tag questions require reassurance or approval, while rising intonations and "hedges" suggest hesitancy (Lakoff, 1975). These speech patterns also reinforce girls' subordination in a patriarchal society. As adults, women are perceived as weak, passive, or disinterested if they do not speak their mind and assert themselves in various situations (Lakoff, 1975; Schur, 1984). Lakoff (1975: p. 51) explains, “... the behavior a woman learns as 'correct' prevents her from being taken seriously as an individual, and further is considered 'correct' and necessary for a woman precisely because society does not consider her seriously as an individual."

Whereas girls are socialized to be emotionally and linguistically expressive, boys are socialized to be emotionally and linguistically inexpressive (Johnson, 2005). Subsequently, boys and men are confronted standards that reinforce heteronormative masculine behavior (Johnson, 2005). Boys learn early on that in tense moments they should remain "cool head[ed]" and in control of their emotions (Johnson, 2005: p. 86; Lorber, 1994). If boys are unable to remain calm and in control, the only socially appropriate emotion to then show is anger (Johnson, 2005; Lorber, 1994). Sattel (1983) suggests that boys are not inexpressive because they have been socialized to control their emotions; rather, they have been socialized to aspire to prestigious and powerful positions (see also Spender, 1985). To illustrate this power, boys and men partake in "unemotional rationality" in which they maintain power and control in various situations (Sattel, 1983: p. 
120). What at first appears as men being inexpressive or aloof may indeed be an intentional decision to reframe from sharing emotions and thereby ensuring that their position remains primary (Sattel, 1983; Spender, 1985). Spender (1985: p. 47) elaborates, "Men who may wish to stay in control of conversation may quite accurately perceive that the disclosure of their emotions leads to a reduction in control, with the result that they may not find the prospect of self-revelation an enticing one."

In addition to learning gender specific linguistic patterns, language serves different functions for girls and boys. Aiming to maintain relationships and establish closeness with their peers, girls' talk is collaboration-oriented (Coates, 2004; Maltz \& Borker, 1982), also referred to as rapport talk (Tannen, 1990). When confronted with conflict, girls use language as a means to compromise, understand, or avoid further conflict. Meanwhile, boys' talk is competition-oriented, "report talk," and aims to promote a dominant status, maintain an audience, and draw attention (Coates, 2004; Maltz \& Borker, 1982; Tannen, 1990). These language practices unfold in children's play groups, which often involves gendered scenarios (Cook-Gumperz, 2004; Thorne, 1997). Similarly, given the amount of time children spend in schools, it is not surprising that gendered language patterns are further solidified through interactions at school (Thorne, 1997). One important type of interaction that is gendered and experienced by many schoolaged children is bullying.

\subsection{Gender Differences in Bullying Behavior}

Simply defined, bullying, also referred to as peer mistreatment or peer aggression, is repeated behavior that intends to hurt, threaten, or isolate a person (Meyer, 2015; Olweus, 1993; Sullivan, 2011). Direct (overt) bullying is described as "open attacks on a victim," whereas indirect (covert) bullying is a subtler form of bullying, such as exclusion or social isolation (Olweus, 1993: p. 10; see also Espelage, Mebane, \& Swearer, 2004). It is reported that $20 \%$ of students ages 12 18 are bullied inside of school while 15\% report being bullied online (National Center for Educational Statistics, 2019). Children partake in various forms of bullying behavior based on their sex. Generally, boys often encounter direct physical forms of bullying, whereas girls often use relational aggression (indirect bullying) as a means to exclude or isolate their peers (Crick \& Grotpeter, 1995; Espelage et al., 2004; Fried \& Fried, 1996; Meyer, 2015; Olweus, 1993; Österman, et al., 1998; Sullivan, 2011).

While there are clear sex differences pertaining to bullying behavior, examining the gender differences offers new insight. Based on one's sex (biological), there are different cultural and societal rules one is expected to fulfill (gender). Boys are expected to aspire to masculine traits, whereas girls are socialized to be feminine (Bem, 1993; Lorber, 1994). Sociolinguistics offers a concrete explanation of how gendered differences of language are socialized and may thereby influence one's bullying behavior, as well as how victims make sense of their experience. For instance, because girls' communication is collaboration-orientated 
(Coates, 2004; Simmons, 2002), it is not surprising that girls often use language as a means of isolating their peers, which is reflected in the high levels of relational-aggression (Simmons, 2002). Meanwhile, boys are socialized and encouraged to use language as a means to assert their dominance and not express themselves, therefore they often respond with physical violence when confronted with conflict (Coates, 2004). This explains the higher rates of overt bullying experienced by boys (Olweus, 1993).

How adults react to children's involvement with bullying is also gendered. When girls vocalize their experiences of being mistreated to adults in school, their accounts are often dismissed or not taken seriously (Simmons, 2002). Overwhelming, girls who voice their victimization are labeled as "tattle tails" (Simmons, 2002), "bossy", "competitive," or "unladylike," and girls who remain non-expressive are deemed "timid" or "nonentity" (Schur, 1984: p. 53). This reflects a speech and interaction double bind for girls; they are scrutinized if they over conform or under conform to various gender norms (Schur, 1984). Adults' response to girl's expressive or non-expressive responses to victimization serves as a form of social control which helps perpetuate gender norms as they pertain to language. While girls are often caught in a double bind, it is socially expected that "boys will be boys" and as a result, boys often verbally and physically act out in class. Such behavior is typically tolerated for boys, whereas girls are reprimanded for similar acts (Simmons, 2002).

\section{Data and Methods}

This study aims to combine the topic of bullying with the discipline of sociolinguistics. Previous bullying studies have found gendered differences in the types of bullying that girls and boys experience. Previous sociolinguistics studies have shown that girls and boys are socialized to use language in gendered ways. As a result, the study's aim is to understand how written accounts from victims is shaped by gender, and thereby, may reinforce gender differences. Our research question is:

1) What gendered linguistic patterns do girls and boys use to explain their bullying experiences?

Understanding any gendered linguistic patterns in how school-aged children make sense of being victimized, may help inform bullying intervention and prevention strategies that are gender specific.

\subsection{Data}

Conducted by Davis and Nixon (2014), the Youth Voice Project is a national survey that focuses primarily on school-aged children and how they experienced and coped with bullying. Throughout 12 states in the US, 31 primary and secondary schools ( 28 public and 3 private) participated and completed an on-line survey $(N=13,177)$. Participating schools received access to the survey via SurveyMonkey. Students took the survey on computers at their schools, during 
which time teachers were available for any technical questions or problems. The survey consisted of 33 multiple-choice questions and 12 open-ended questions, for a total of 45 questions. Ages of participants ranged from 11 to 19 years old and $33 \%$ of the total number of students in the study were in high school (9th-12th grade), 57\% were in middle school (6th-8th), and $10 \%$ were in elementary school (5th grade) (for a full descriptions of the survey, see Davis and Nixon, 2014).

\subsection{Sampling Criteria and Characteristics}

The sample for this study was contingent on satisfying three criteria. First, the sample was limited to include only middle school students. Higher rates of bullying are reported by middle school children (Olweus, 1993); therefore, students in grades 6th-8th were the focus of this study. Second, given that previous studies rely on Olweus' definition of bullying, the sample was limited to respondents who satisfied Olweus's definition of bullying, which categorizes bullying as repeated unwanted behavior that takes place over time. Students were included in the sample if they answered, "every day," "once a week," or "two or three times a week" to at least one of the two following questions:

Q29. In the past month, how often have students at your school hurt you emotionally or excluded you?

Q30. In the past month, how often have students at your school threatened to hurt you or hurt you physically?

The third criteria included only respondents who offered a written answer to the coding unit. Children were asked a series of close-ended questions, regarding the type of bullying they experienced and who the perpetrator was (see Appendix B). Following these questions was an open-ended question, which allowed children to explain more thoroughly what they experienced. Written responses to the following open-ended question was the coding unit:

Q52. If you feel comfortable, please describe what happened to you [when you were mistreated by a peer]. Because this is a confidential survey, please also tell an adult you trust at school about what happened if you have not already done that. Please do not include any names.

In an attempt to capture more fully the children's voice, verbatim text is used within the findings. Grammatical and spelling errors were not corrected since we wanted to stay true to the children's original written responses.

Once the three criteria were met, the sample yielded a total of 362 girls and 239 boys for a total of 601 respondents. Of the sample, most were 12 or 13 years old. There were very few respondents who were 15 or older. The sample was almost split equally between nonwhites and whites. More than half of the students lived in a two-parent household and most students did not receive a free lunch. Further, most students were not in a special education program or reported having a physical disability. For a detailed breakdown of the demographic variables by gender see Table 1 . 
Table 1. Descriptive statistics of middle school girls and boys.

\begin{tabular}{|c|c|c|}
\hline \multirow[t]{2}{*}{ Variables } & \multicolumn{2}{|c|}{ Percentages } \\
\hline & $\begin{array}{c}\text { Girls } \\
(n=362)\end{array}$ & $\begin{array}{c}\text { Boys } \\
(n=239)\end{array}$ \\
\hline \multicolumn{3}{|c|}{ Grade } \\
\hline 6th Grade & $36 \%$ & $41 \%$ \\
\hline 7th Grade & $35 \%$ & $34 \%$ \\
\hline 8th Grade & $29 \%$ & $24 \%$ \\
\hline \multicolumn{3}{|c|}{ Race } \\
\hline White & $61 \%$ & $58 \%$ \\
\hline Non-White & $39 \%$ & $42 \%$ \\
\hline \multicolumn{3}{|c|}{ Family Structure } \\
\hline 2-Parent & $58 \%$ & $64 \%$ \\
\hline 1 Parent & $42 \%$ & $36 \%$ \\
\hline \multicolumn{3}{|c|}{ Reduced Lunch } \\
\hline Yes & $37 \%$ & $32 \%$ \\
\hline No & $63 \%$ & $68 \%$ \\
\hline \multicolumn{3}{|c|}{ Immigrated } \\
\hline Yes & $7 \%$ & $10 \%$ \\
\hline No & $93 \%$ & $90 \%$ \\
\hline \multicolumn{3}{|c|}{ Physical Disability } \\
\hline Yes & $10 \%$ & $8 \%$ \\
\hline No & $90 \%$ & $92 \%$ \\
\hline \multicolumn{3}{|c|}{ Special Education } \\
\hline Yes & $11 \%$ & $12 \%$ \\
\hline No & $89 \%$ & $88 \%$ \\
\hline
\end{tabular}

\subsection{Analytic Strategy}

A mixed method approach, which included a qualitative content analysis and Ordinary Least Squares (OLS) regression, was used to answer the outlined research question. Whereas quantitative content analysis is mainly deductive and requires the researcher to count words and focus on the objective content of text, qualitative content analysis surpasses this requirement and is inductive, enabling the researcher to examine the subjective interpretation of the underlying meaning of the initial counts (Graneheim \& Lundman, 2004; Krippendorff, 2018; Morgan, 1993). Based on the research question, we were most interested in understanding what differences in word counts existed between girls and boys, and what might explain these differences. A summative approach to qualitative content analysis was used, which first required us to identify the quantitative differences in the number of words used by respondents, and then "... [understand] the contextual use of the words or content" (Hsieh \& Shannon, 2005: p. 1285).

First, a manifest analysis was completed. This step required us to code the 
"visible and obvious" content; a word count of each response (Bengtsson, 2016; Graneheim \& Lundman, 2004). The "word count" function in Microsoft Word was used for each entry. For simplicity, word counts were grouped in categories groups of five (see Table 2). Girls fell into categories with more word counts than boys. Approximately $12 \%$ of girls used 26 - 30 words in their response, whereas less than $7 \%$ of boys fell within this category. Girls (28.5\%) used 31 or more words more than boys (10\%).

To boost the validity of the manifest analysis, an Ordinary Least Squares (OLS) regression analysis was run. First, statistically significant of the number of words by girls and boys was applied (see Table 3). Next, the data were split by grade to examine if there were statistically significant gender differences in word count use within each middle school grade level (see Figure 1 and Figure 2).

Next, a latent analysis was applied to discern and interpret the deeper meaning of the manifest content (Bengtsson, 2016; Graneheim \& Lundman, 2004). From the manifest analysis, we can conclude that girls used more words to describe their experiences of being bullied compared to boys. A latent analysis of this finding required us to revisit the literature to explain why girls use more language than boys.

Table 2. Counts of the number of words used.

\begin{tabular}{ccc}
\hline Word Count & Girls $(\boldsymbol{n}=362)$ & Boys $(\boldsymbol{n}=\mathbf{2 3 9})$ \\
\hline $1-5$ words & $16(4.4 \%)$ & $35(14.6 \%)$ \\
$6-10$ words & $60(16.6 \%)$ & $48(20.1 \%)$ \\
$11-15$ words & $53(14.6 \%)$ & $49(20.5 \%)$ \\
$16-20$ words & $37(10.2 \%)$ & $49(20.5 \%)$ \\
$21-25$ words & $50(13.8 \%)$ & $19(8 \%)$ \\
$26-30$ words & $43(11.9 \%)$ & $15(6.3 \%)$ \\
$31+$ words & $103(28.5 \%)$ & $24(10 \%)$
\end{tabular}

Table 3. Ordinary least squares regression of word count on gender $(n=601)$.

\begin{tabular}{ccccc}
\hline & \multicolumn{2}{c}{ Model 1 } & \multicolumn{2}{c}{ Model2 } \\
\hline Variables & $b$ & $S E$ & $b$ & $S E$ \\
\hline Gender & $10.034^{* * *}$ & 2.066 & $9.444^{* * *}$ & 2.233 \\
Race & & -3.823 & 2.267 \\
Grade & & 2.433 & 1.365 \\
Family Structure & & -0.092 & 2.350 \\
Reduced Lunch & & -0.400 & 2.439 \\
Immigration & & -0.549 & 4.048 \\
Physical Disability & & & -2.556 & 3.922 \\
Special Education & & & -5.668 & 3.922 \\
Intercept & $17.640^{\star * *}$ & 1.603 & $14.395^{\star *}$ & 4.843 \\
R $^{2}$ & 0.038 & & 0.051 & \\
\hline
\end{tabular}

Note. ${ }^{*} p<0.05 .{ }^{* *} p<0.01 .{ }^{* *} p<0.001$. 


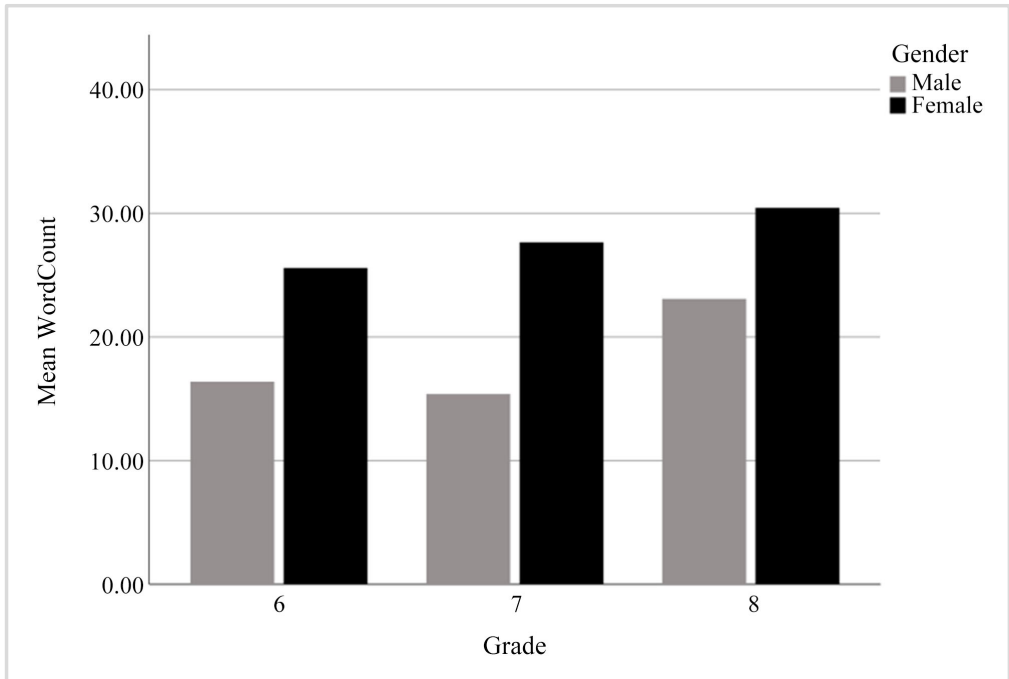

Figure 1. Mean of word count by grade with outlier.

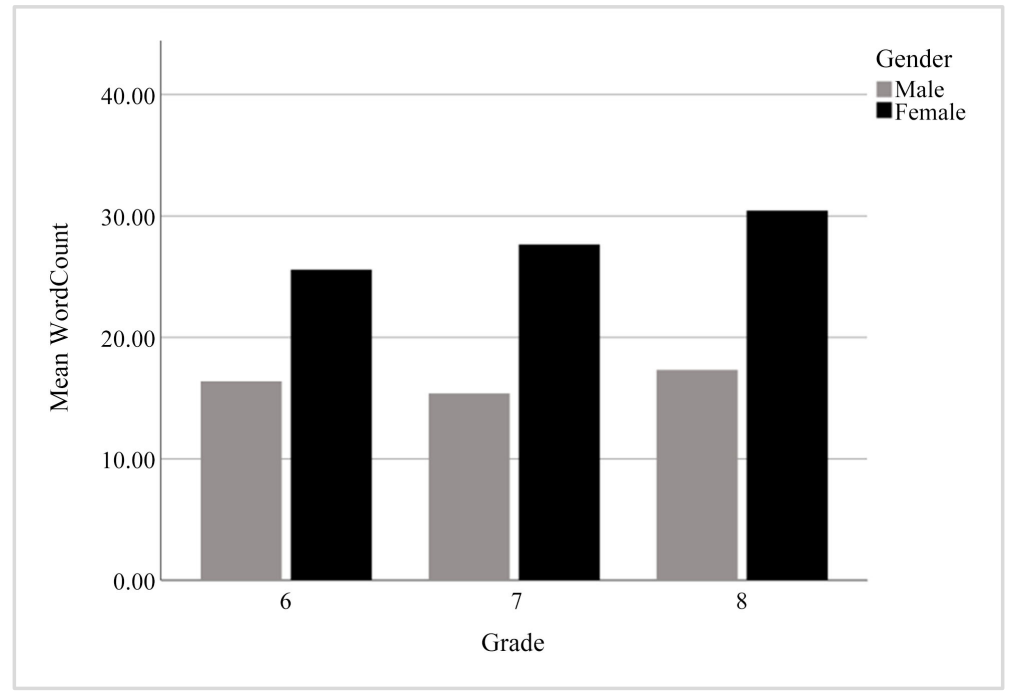

Figure 2. Mean of word count by grade without outlier.

\section{Findings}

When prompted to reflect on what they experienced in regard to bullying, some middle school girls and boys offered qualitative answers in addition to the closed-ended questions. Two key findings are outlined; The first finding includes how much information was shared (quantity/word count) and the gendered explanation of these counts. The second finding uncovered the gendered patterns in how girls and boys wrote their responses. This included how gendered patterns of communication helped explain why girls and boys choose to include or omit certain details of their experiences, as well as how they wrote about their experiences (i.e. omitting "I" statements or storytelling). Within the second theme, two sub-themes emerged, including girls' use of clarifying statements and boys' displaying a tough guise, in which they demonstrated masculine traits of strengthen and control, thereby negating any signs of vulnerability or weakness 
(Katz \& Earp, 1999; see also Connell, 2005). At times, the categories for the findings were not mutually exclusive. For instance, boys' responses that had shorter sentences may also demonstrate their attempts to enact a tough guise and confirm their masculinity by being brief with words.

\subsection{Quantity of Words}

Aligning with the literature, girls were more verbose than boys in their responses. After completing a word count for all participants, the highest percentage of boys (20.5\%) used between 11 - 15 or 16 - 20 words in their response, whereas the highest percentage of girls (28.4\%) used over 31 words in their response (see Table 2). Having the opportunity to write their responses offers the participants a level of anonymity that is not achievable through face-to-face interviews or participant observation. Therefore, girls' lengthy responses sheds light on their willingness to convey their stories, whereas boys' lack of lengthy responses may reflect how they have been socialized to be verbally and emotionally inexpressive.

Furthermore, the number of words girls used compared to boys was statistically significant, even when including demographic controls. Girls on average used $9.444(p<0.000)$ more words than boys when describing their experiences (see Table 3 ). Over the course of their education, students acquire more vocabulary (see Coates, 2004). To test this, we examined whether there were gender effects within each grade level pertaining to quantity of words used. Figure 1 and Figure 2 display the differences in the mean use of words for girls and boys by grade. When first running the analysis, it appeared that only grades $6^{\text {th }}$ and $7^{\text {th }}$ were statistically significant and that $8^{\text {th }}$ grade gender differences did not reach significance (Figure 1). However, when examining the data, there was an $8^{\text {th }}$ grade boy who used 346 words to describe his experience. He was a clear outlier and once he was removed from this analysis, we confirmed that there was a significant difference between girls and boys for all grade levels (Figure 2). In fact, the amount of words $8^{\text {th }}$ grade boys used is only slightly more than the number of words used in $7^{\text {th }}$ grade, whereas girls continued to increase the use of their words to describe their experiences through all grade levels. This may support the notion that as boys age, they become more rigid in their use of words and expression of emotions, whereas girls continue to increase their vocabulary over time.

\subsection{Content of Responses}

Once the manifest analysis was completed and we concluded that girls had longer responses compared to boys, we then completed the latent analysis. This required us consider, in light of previous literature, why girls wrote more thorough explanations than boys. Girls offered more details pertaining to their experience of being bullied, whereas boy's responses were more "matter of fact." Girls often included how the situation made them feel, events leading up to the incident, 
who was involved, and what happened after the incident. For instance, the following example illustrates one girl's experience with bullying in successive grades.

There are a couple of people last year, who would make fun of me because of my being a little overweight body type, and they would constantly pick on me, and talk about me behind my back, but this year, I feel she is kind of doing it, because when I was walking from my bus stop, she started to yell that $1 \mathrm{~m}$ fat, and I don't belong on this planet, but when P $m$ at school, she'll smile at me, and talk to me once in a while like nothings happened. And I don't get it. I think when she's around me, she's nice, and when she's not, she constantly talks about me ... I just want it to stop ... and for people to like me the way I am ...

This example illustrates how the young girl desired to be treated, with respect and acceptance by her peers, which is apparent by the clarity in her written voice. In an attempt to understand the motives of her attacker, this girl's account also sheds insight into the insidious nature of relational aggression (see Simmons, 2002).

Boys, on the other hand, offered more concise responses (i.e., they often shared the story's beginning, middle, or end). Many of the boy's responses lacked a full description of the event. This is exemplified in the following comment made by a boy:

Last year and all through fourth grade there was a group of people who consistently caused drama that would always end in someone's feelings getting hurt. That same group of people started spreading rumors that I was a drug dealer/user.

Although it is clear that this boy experienced bullying over a few years, he does not offer information pertaining to how he responded or how the routine mistreatment made him feel. He does, however, speak about the general occurrence, indicating that the perpetrators were mistreating other students as well, but he was not specific in terms of how these students were being mistreated. Similarly, other boys' responses included:

I have been choked, pushed, punched.

I got attacked.

I got beat the crap out of many times

Got called names and got pushed and hit

Force fed, swirly, punched, etc.

A kid in math hits me about once a week or makes fun of me

The other day just walking along outside, some kid grabbed me and twisted my wrist.

These quotes provide a good example of the type of bullying boys experienced, as well as the brevity in describing their experiences.

Some boys' responses included emotions and efficacy against bullying, such as voicing their general attitude towards bullying behavior. For instance, a white boy in $6^{\text {th }}$ grade wrote, “... The system for bullying discipline is terrible. Every- 
thing is just swept under the rug." In this regard, the boy's emotion was not a focus of his experience. If he did present an emotion, it was more about his disapproval of how a school handled bullying. In this way, boys deflected their personal emotions from the event and shifted the attention to an external concern.

\subsection{Attempts to Save Their Reputation}

Another finding from latent analysis revealed respondents' attempt to "set the record straight" by stating their opinion or interpretation of various rumors or defending/excusing the behavior. The content in these explanations were gendered. Specifically, girls included clarifying statements, as though they were talking directly to the reader and defending themselves. Clarifying statements were made after some girls described various rumors that were spread about them, explaining that such rumors "are not true," as exemplified in the following four accounts:

My friend was saying stuff to my other friend and it was not true (it was about me) and she was geting on my nerves. Also i said something in fith grade and it was funny to them but not to me and they brought it up this year.

My former best friend told lies to my friends. She said things like, "She thinks your fat and ugly." Or, "You have ugly clothing and your poor." She spread a rumor that I said these things about my friends wchich is not true.

My former best friend told my other friends that I said that they are fat and ugly, this is definitely not true because my parents have teached me that bullying is not safe and I can get in trouble.

Three girls started rumors that $i$ waz pregnent and that $i$ had razor blades then to find out that this was not true they then tryed to jump me $i$ hve had theses girls and others Call me fat ugly and other very unapproipate names

Girls' thorough responses and use of clarifying statements may be an attempt to use language as a means of "righting" a "wrong" they experienced. Given that reputation is an important part of adolescence for girls (Simmons, 2002), some girls may have felt the need to protect their reputation by informing the researchers that the reason for the bullying behavior was unwarranted because it simply was not true. In this essence, these girls may have been trying to save their reputation by clarifying that the rumors spread about them are not true.

On the other hand, boys' use of clarifying statements was not to necessarily "set the record straight," but instead to explain the insignificance of the event or dismissing the event as merely a way for other boys to assert themselves. The following written accounts reflect this:

Well $i$ ment threatened on the questions but it wasn't bad those people were just trying to act tuff

People are just that way, they will do what they have to to get the respect or things they want.

They would say names and make jokes about me that didnt need to be said so I held it in and just laughed about it 
Ive been hit and kicked by some kids trying to impress others, more like show off

Well $i$ was pushed in a locker no biggy

They just call everyone names because, well you know we are all boys.

These responses suggest that some boys were putting on a "tough guise," downplaying the severity of what they experienced and even rationalizing that they were targeted because their peers were attempting to "act tuff" (Connell, 2005; Katz \& Earp, 1999). Such accounts may also be boys' attempts to remain "cool head[ed]" (Johnson, 2005: p. 86) or display "unemotional rationality" (Sattel, 1983). Common also, were boys making general statements and not specifying identifying individual peers who harassed them. Linguistically, making generalizations and taking the focus off of "I" statements serves to shift the victimization to a general "other," thereby avoiding direct victimization. As a result, boys are able to maintain their position of power by avoiding "I" statements and explaining that the acts were common occurrences and a result of peers trying to assert themselves.

Boys who attempted to rationalize the motives of their attackers were reflective of masculine traits may serve to reinforce the notion that "boys will be boys" and the (physical) bullying they experience is a "natural" component of their childhood. These responses suggest that some boys have indeed embodied this notion instead of admitting their victim status; these boys have accepted that their peers may use them as targets to "show off."

\section{Discussion}

When prompted to reflect on what they experienced in regard to bullying, some middle school girls and boys offered qualitative feedback in addition to completing the closed-ended questions. Based on what children chose to include in their responses, two key findings pertaining to gender linguistics are outlined. These findings include how much was shared and the underlying gendered meaning of how the information was presented.

\subsection{Tell Me about It}

The quantity of how much girls and boys choose to share (as illustrated in the word counts) is very telling of gender and linguistic differences. Aligning with the literature (Coates, 2004; Weatherall, 2002), girls in this sample were more verbose than boys. Given that girls are socialized to be more expressive, this is not surprising. However, within society at large, women's voices are often silenced and are not given the same amount of respect as men's voices (Johnson, 2005; Lakoff, 1975; Meyerhoff, 2004). This reflects our patriarchal society, in which men maintain positions of power and authority and masculine traits are ranked superior to female traits (Bem, 1993; Johnson, 2005; Speer, 2005). As a result, not only are women's voices not given the same respect as men's, their voices and perspectives are greatly overlooked or silenced. Regardless, girls in this sample did not hold back in offering full explanations. 
On the other hand, boys offered fewer and shorter responses compared to girls. However, to argue that boys did not share a lot because they are socialized to be non-expressive is too simple of a conclusion. As noted previously, sociolinguists suggest that what men do not say, is just as important as what they do say. Sattel (1983: p. 120) explains, "Keeping cool, keeping distant as others challenge you or make demands upon you, is a strategy for keeping the upper hand." Boys' low response rate to the open-ended question may therefore be an intentional attempt to control the situation and maintain their position of power by not divulging what they experienced and thereby admitting to being victimized.

\subsection{It's Not What You Say, It's How You Say It}

In addition to the quantity of words demonstrating gender differences, how girls and boys shared their stories is gendered. Girls offered more descriptive details of who was involved, why the situation occurred, how the situation made them feel, how they responded to the situation, and/or what happened as a result of their actions. On the other hand, boys overwhelming shared information specific to what happened, generally leaving out their emotions and details leading up to and following the event. The inclusion or lack of such details may be gendered attempts to save one's reputation. Unique to the girls was the tendency to defend themselves, whereas boys attempted to save their reputation was by coming off "cool head[ed]" and using a "tough guise".

The motives of these responses would be pure speculation, but important conclusions can be drawn from focusing on the language choices that girls and boys made. For instance, girls were using rapport talk or collaboration-oriented talk (Coates, 2004; Maltz \& Borker, 1982; Tannen, 1990) when they shared their feelings and relayed in-depth stories. Girls' responses mirrored storytelling, in which they reflected on their self-esteem being lowered, feeling sad, depressed, "feeling left out," "lonely," or "out of the loop." Girls have been socialized to be more expressive, detailed oriented, and share their emotions. Therefore, using descriptive and emotional words aligns with gender socialization and traditional gender rules. By painting a complete picture of the bullying incident, their response to the incident, and perceived truthfulness of the incident, girls may have been attempting to save their reputation. By providing a thorough explanation of their experience, readers may conclude the untruthfulness of the incident and thereby side with the respondent's perspective.

Some boys avoided admitting their victim status and instead described their perpetrators as "just trying to act tuff" or "get respect," which suggests that these boys were partaking in report talk or competition-oriented talk (see Coates, 2004; Maltz \& Borker, 1982; Tannen, 1990). Boys often talk less than girls, however when they do talk, it is often only to make them look in control, competitive, or independent (Coates, 2004; Tannen, 1990). Therefore, when boys described their bullies as "just kids trying to impress others," they are indirectly supporting masculine traits that demand control, competition, and intimidation. These victims do not readily (if at all) admit their victim status, since to do so 
would call into question their masculinity. This type of talk allowed for boys to have a "tough guise" and provided an outlet to appear "cool head[ed]".

\section{Limitations}

A key goal of this study was to understand the gendered differences in how girls and boys explain their experiences of being bullied. Conducting a qualitative content analysis enabled us to examine the trends and themes of such accounts. However, the quantity and thoroughness of responses might also be influenced by the children's typing abilities. If children lacked the patience to type their full answers or lacked typing skills, their accounts were not captured in this data. Also, because we relied on the open-ended responses of a national survey, we were not able to probe for more thorough responses from any of the participants. Had the data relied on face-to-face interviews, more insight from sociolinguistics could have been applied. For instance, utterances, pauses, and inflections in voice could have telling gendered differences that are not captured in written responses (see Coates, 2004; Tannen, 1990). Further, when the boys were speaking, we could have ascertained through body language the difference between what they were saying and how they were saying it.

Another key goal of this study enabled us to use children's voices as a standpoint to better understand the lived experiences of children who have experienced bullying. Although we use children's direct words for analysis, ultimately, it was our interpretation of the data. Future studies might consider incorporating children in the research process. By enabling children to devise the questions and highlight the themes they find most significant, such studies have the potential to shed new light into understanding bullying directly from those who experience it.

\section{Conclusion}

At first glance gendered differences in how girls and boys described their experiences of being bullied may suggest that girls take incidences of bullying more seriously (or "to heart") than boys. Boys, on the other hand, let incidences of bullying simply "roll of their backs". However, when taking into account insight from sociolinguistics, we recognize that these gendered differences are reflected in language patterns that girls and boys learn. In other words, girls and boys talk about their experiences of being bullied in ways that they have been taught to communicate. Lakoff (1975) argues that linguistic change and social change are inseparable. Therefore, to remedy women's secondary status to men, women may opt to adapt men's linguistic patterns, which she defines as "neutral language" (Lakoff, 1975; Speer, 2005). Likewise, one might propose that for women to gain the same respect, power, and control, they should indeed become mensuggesting that women, as the second sex, cannot merit power or respect without adopting masculine traits. Instead of proposing women let go of their speech patterns and adopt men's speech patterns, others argue that each linguistic pat- 
tern has its benefits (Tannen, 1990) and women should not assimilate to men's speech patterns to gain respect. Given that girls are more proficient and expressive than boys, others argue that boys have a lot to learn from girls' speech patterns.

How adults react to children's involvement with bullying is also gendered. Therefore, parents and educators should consider that gender roles impact how children perceive, explain, and make sense of their experiences of being bullied. Intervention and prevention techniques must be gender specific. For example, adults' response to girl's expressive or non-expressive responses to victimization serves as a form of social control which helps perpetuate gender norms as they pertain to language. Often, when girls vocalize their experiences of being mistreated to adults in school, their accounts are often dismissed or not taken seriously (Simmons, 2002). Girls who voice their victimization are labeled as "tattle tails" (Simmons, 2002), "bossy", "competitive," or "unladylike," and girls who remain non-expressive are deemed "timid" or "nonentity" (Schur, 1984: p. 53). It would therefore serve parents and educators to listen to girls' accounts of bullying, instead of writing off such verbosity as typical or unimportant girl talk (see Simmons, 2002). Adults might achieve this by encouraging girls to talk through their experiences, either vocally or in written form. Girls' explanations of experiencing bullying can offer adults valuable insight into the insidious nature of relational aggression.

On the other hand, it is socially expected that "boys will be boys" and as a result, boys often verbally and physically act out in class. Such behavior is typically tolerated for boys, whereas girls are reprimanded for similar acts (Simmons, 2002). This mentality excuses boys' involvement with direct (physical) bullying and minimizes the perceived harm inflicted to male victims of bullying. Adults can remedy this by being aware of gender socialization, in which boys learn to control their emotions as a means of maintaining their power in various situations (Connell, 2005; Sattel, 1983; Spender, 1985). While men maintain positions of power within our patriarchal society, their patterns of language reinforce a tough guise, which serves to silence men. The rationalization of actions, thoughts, and feelings are quintessential markers of masculinity, and as suggested by this study, boys rationalize their frustration and anger with a justification of why they could and should inflict harm on the aggressor. Instead of attempting to change how boys use language, parents and educators would benefit by working with skills boys already possess. For instance, boys might be encouraged to tell stories in the third person about their experiences with bullying. Using this writing method may help boys process their emotions in a non-confrontational way (see Pennebaker \& Ferrel, 2013).

\section{Conflicts of Interest}

The authors declare no conflicts of interest regarding the publication of this paper. 


\section{References}

Bem, S. L. (1993). The Lenses of Gender: Transforming the Debate on Sexual Inequality. Yale University Press.

Bengtsson, M. (2016). How to Plan and Perform a Qualitative Study Using Content Analysis. NursingPlus Open, 2, 8-14. https://doi.org/10.1016/j.npls.2016.01.001

Cameron, D. (1992). Feminism and Linguistic Theory. Palgrave Macmillan. https://doi.org/10.1007/978-1-349-22334-3

Coates, J. (2004). Women, Men and Language. Routledge.

Connell, R.W. (2005). Masculinities. Pearson Education Limited.

Cook-Gumperz, J. (2004). Public Discourse and the Private Life of Little Girls: Language and Woman's Place and Language Socialization. In M. Bucholtz (Eds.), Language and Woman's Place. Text and Commentaries (pp. 195-201). Oxford University Press.

Crick, N. R., \& Grotpeter, J. K. (1995). Relational Aggression, Gender, and Social-Psychological Adjustment. Child Development, 66, 710-722. https://doi.org/10.2307/1131945

Davis, S., \& Nixon, C. (2014). Youth Voice Project: Student Insights into Bullying and Peer Mistreatment. Research Press Publisher

Espelage, D. L., Mebane, S. E., \& Swearer, S. M. (2004). Gender Differences in Bullying: Moving beyond Mean Level Differences. In D. L. Espelage, \& S. M. Swearer, (Eds.), Bullying in American Schools: A Social-Ecological Perspective on Prevention and Intervention (pp. 37-58). Routledge. https://doi.org/10.4324/9781410609700-10

Fried, S., \& Fried, P. (1996). Bullies and Victims: Helping Your Child Survive the Schoolyard Battlefield. M. Evans \& Company.

Graneheim, U. H., \& Lundman, B. (2004). Qualitative Content Analysis in Nursing Research: Concepts, Procedures and Measures to Achieve Trustworthiness. Nurse Education Today, 24, 105-112. https://doi.org/10.1016/j.nedt.2003.10.001

Hsieh, H. F., \& Shannon, S. E. (2005). Three Approaches to Qualitative Content Analysis. Qualitative Health Research, 15, 1277-1288. https://doi.org/10.1177\%2F1049732305276687

Johnson, A. G. (2005). The Gender Knot: Unraveling Our Patriarchal Legacy. Temple University Press.

Katz, J., \& Earp, J. (1999). Tough Guise [DVD]. Media Education Foundation.

Krippendorff, K. (2018). Content Analysis: An Introduction to Its Methodology. Sage Publications.

Lakoff, R. (1975). Language and Woman's Place. Harper and Row.

Lorber, J. (1994). Paradoxes of Gender. Yale University Press.

Maltz, D. N., \& Borker, R.A. (1982). A Cultural Approach to Male-Female Miscommunication. In L. Monaghan, \& J. E. Goodman (Eds.), A Cultural Approach to Interpersonal Communication: Essential Readings (pp.168-185). Blackwell Publishing.

Meyer, E. J. (2015). Gender, Bullying, and Harassment: Strategies to End Sexism and Homophobia in Schools. Teachers College Press.

Meyerhoff, M. (2004). Doing and Saying: Some Words on Women's Silence. In M. Bucholtz (Ed.), Language and Woman's Place. Text and Commentaries (pp. 209-215). Oxford University Press.

Morgan, D. L. (1993). Qualitative Content Analysis: A Guide to Paths Not Taken. Qualitative Health Research, 3, 112-121. https://doi.org/10.1177\%2F104973239300300107

National Center for Educational Statistics (2019). Student Reports of Bullying: Results 
from the 2017 School Crime Supplement to the National Victimization Survey. US Department of Education. http://nces.ed.gov/pubsearch/pubsinfo.asp?pubid=2015056

Olweus, D. (1993). Bullying at School: What We Know and What We Can Do. Blackwell Publishing.

Österman, K., Björkqvist, K., Lagerspetz, K. M., Kaukiainen, A., Landau, S. F., Frączek, A., \& Caprara, G. V. (1998). Cross-Cultural Evidence of Female Indirect Aggression. Aggressive Behavior, 24, 1-8. https://doi.org/10.1002/(SICI)1098-2337(1998)24:1\%3C1::AID-AB1\%3E3.0.CO;2-R

Pennebaker, J., \& Ferrel, J. D. (2013). Can Expressive Writing Change Emotions? An Oblique Answer to the Wrong Question. In D. Hermans, B. Rimé, \& B. Mesquita (Eds.), Changing Emotions (pp. 197-200). Psychology Press.

https://doi.org/10.4324/9780203075630-34

Sattel, J. W. (1983). Men, Inexpressiveness, and Power. In B. Thorne, C. Kramarae, \& N. Kenley (Eds.), Language, Gender and Society (pp. 118-123). Newbury House Publishers, Inc.

Schieffelin, B. B., \& Ochs, E. (1986). Language Socialization. Annual Review of Anthropology, 15, 163-191. https://doi.org/10.1146/annurev.an.15.100186.001115

Schur, E. M. (1984). Labeling Women Deviant: Gender, Stigma, and Social Control. Temple University Press.

Simmons, R. (2002). Odd Girl Out: The Hidden Culture of Aggression in Girls. Harcourt, Inc.

Speer, S. A. (2005). Gender Talk: Feminism, Discourse and Conversation Analysis. Routledge.

Spender, D. (1985). Man Made Language (2nd ed.). Routledge \& Kegan Paul.

Sullivan, K. (2011). The Anti-Bullying Handbook (2nd ed.). SAGE Books. https://doi.org/10.4135/9781446289006

Tannen, D. (1990). You Just Don't Understand: Women and Men in Conversation. Ballantine Books.

Thorne, B. (1997). Gender Play: Girls and Boys in School. Rutgers University Press.

Trudgill, P. (1995). Sociolinguistics: An Introduction to Language and Society. Penguin Books.

Weatherall, A. (2002). Gender, Language, and Discourse. Routledge.

West, C., \& Zimmerman, D. H. (1987). Doing Gender. Gender and Society, 1, 125-151. https://doi.org/10.1177\%2F0891243287001002002 